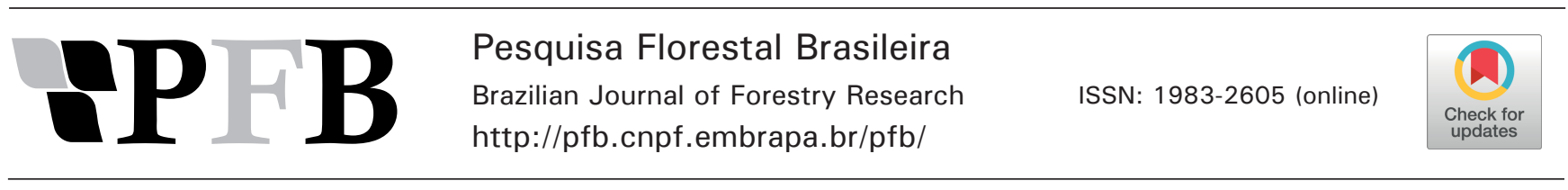

\title{
Modelagem da biomassa da regeneração natural em plantio de Pinus
}

\author{
Rafael Cubas ${ }^{1 *}$, Emanuel Arnoni Costa², César Augusto Guimarães Finger ${ }^{2}$, Viviane Zaniz Maydanchen ${ }^{1}$ \\ ${ }^{1}$ Universidade do Contestado, Rua Roberto Elke, 85, CEP 89460-000, Canoinhas, SC, Brasil \\ ${ }^{2}$ Universidade Federal de Santa Maria, Av. Roraima, 1.000, CEP 97105-900, Santa Maria, RS, Brasil
}

"Autor correspondente:

florestal.rafael@gmail.com

Termos para indexação:

Peso

Copa

Pinus taeda

Index terms

Weight

Crown

Pinus taeda

Histórico do artigo:

Recebido em 22/10/2016

Aprovado em 15/09/2016

Publicado em 30/09/2016

doi: 10.4336/2016.pfb.36.87.1091
Resumo - Dados confiáveis de biomassa são muito importantes na avaliação de ecossistemas, e auxiliam no entendimento da contribuição das florestas nas mudanças climáticas. Variáveis que descrevem o porte da árvore, como diâmetro e altura, estão associadas diretamente com a biomassa, o que permite o uso de modelos de regressão para a estimativa desse elemento. Este trabalho se propôs estimar, por modelos de regressão, a biomassa de diferentes compartimentos de árvores de regeneração natural em um plantio de Pinus taeda L. Os dados foram obtidos por meio do método destrutivo direto, utilizando-se 100 árvores selecionadas aleatoriamente no sub-bosque de um povoamento de $P$. taeda. Foram analisados três modelos aritméticos, três logarítmicos e dois modelos desenvolvidos pelo processo Stepwise. As equações logarítmicas desenvolvidas pelo procedimento Stepwise apresentaram as melhores estimativas para a biomassa aérea total e do fuste. Entretanto, para os compartimentos acículas e galhos, os melhores ajustes foram observados com o modelo de Husch, e para a predição da biomassa do sistema radicular, o modelo de Berkhout mostrou-se o mais adequado.

\section{Modeling natural regeneration biomass of Pinus stand}

\section{Introdução}

A biomassa das árvores pode ser vista tanto como uma medida de produção quanto como medida do tamanho dos indivíduos arbóreos (Batista et al., 2014). É um instrumento útil na avaliação de ecossistemas, em virtude da aplicação na análise de conversão de energia, ciclagem de nutrientes e absorção e armazenagem de energia solar, entre outros (Campos, 1991, Carbonera Pereira et al., 1997). Sua medição também possibilita avaliar a importância das florestas nas mudanças climáticas, tendo em vista que as florestas em crescimento absorvem $\mathrm{CO}_{2}$ da atmosfera e armazenam carbono em sua biomassa, formando grandes reservatórios desse elemento (Silveira et al., 2008).

A biomassa reflete não só a árvore como um todo, mas também os seus diferentes componentes, tais como a porção aérea e subterrânea (Batista et al., 2014). As quantidades de biomassa podem ser obtidas através do método direto ou destrutivo ou pelo método indireto. 
Pelo método direto os dados são obtidos com base nas medidas feitas imediatamente após o corte das árvores (Lima et al., 2012), o que pode resultar em custo elevado na obtenção da biomassa (Silveira et al., 2008). O método indireto refere-se ao ajuste ou o desenvolvimento de modelos estatísticos, utilizando variáveis que descrevem as dimensões da árvore, como diâmetro da base, diâmetro à altura do peito, altura, diâmetro da copa, dentre outras (Miranda et al., 2011; Fayolle et al., 2013). De acordo com Schikowski et al. (2013), o procedimento para a aplicação da técnica de regressão consiste em cortar algumas árvores da área de estudo e medir a massa, diâmetros à altura do peito, altura e densidade e, posteriormente, relacionar estes parâmetros com a massa da árvore, testando e selecionando um modelo matemático, que reflita o melhor ajuste. Segundo Soares et al. (2012), esse método é preferencialmente utilizado para facilitar o trabalho de campo e diminuir o custo de coleta de dados.

Várias pesquisas utilizando o método indireto para determinação da biomassa foram conduzidas em povoamentos de Pinus spp. (Watzlawick \& Caldeira, 2004; Ritchie et al., 2013; Schumacher et al., 2013). Entretanto, com esta mesma finalidade não há estudos em regeneração natural de Pinus taeda $\mathrm{L}$.

Assim, o objetivo do presente estudo foi estimar através de modelos estatísticos a biomassa seca total e nos compartimentos: acículas, galhos, fustes e raízes de árvores de regeneração natural de Pinus taeda L.

\section{Material e métodos}

O estudo foi realizado na Floresta Nacional de Três Barras, localizada no Município de Três Barras, SC, $26^{\circ} 12^{\prime} 08^{\prime}$ 'S e $50^{\circ} 18^{\prime} 21^{\prime \prime} \mathrm{W}$. O clima da região segundo a classificação de Köppen é do tipo Cfb, temperado, sem estação seca e com verão brando. A precipitação média anual é de $1.588 \mathrm{~mm}$ (Epagri, 2001) e a temperatura média do mês mais frio é de $11,7^{\circ} \mathrm{C}$ em julho e do mês mais quente é de $21,3{ }^{\circ} \mathrm{C}$, em janeiro. A altitude é de $730 \mathrm{~m}$ com relevo plano e ocorrência frequente de geadas (Marques, 2007).

\section{Obtenção dos dados}

Um total de 100 árvores de regeneração natural presentes no sub-bosque em povoamento de 2,98 ha de Pinus taeda foram amostradas aleatoriamente, cobrindo a amplitude de diâmetro (medido à $0,3 \mathrm{~m}$ do nível do solo) de $0,96 \mathrm{~cm}$ à $6,05 \mathrm{~cm}$ e amplitude de altura entre 1,46 $\mathrm{m}$ e 7,4 m. As árvores selecionadas tiveram medidas as variáveis: diâmetro a $0,3 \mathrm{~m}$ do nível do solo $\left(\mathrm{d}_{0,3}\right)$; altura total (h); altura de inserção da copa, correspondente ao primeiro galho vivo (hic); e comprimento de copa (cc).

\section{Determinação da biomassa}

Os dados de biomassa foram coletados em campo mediante o uso do método destrutivo. Para cada árvore foi realizada a separação das partes em compartimentos: acículas, galhos vivos, fustes e raízes, sendo pesados separadamente em balança digital com precisão de $0,1 \mathrm{~g}$, para a quantificação da biomassa verde. Antes da pesagem, as raízes de cada árvore amostrada foram lavadas, para retirada de solo aderido ao material.

Para a determinação da biomassa seca, foram tomadas amostras das acículas na ponta, meio e base da copa, perfazendo um número aproximado de três amostras em cada copa. O mesmo procedimento foi adotado para os galhos. No fuste foram retirados discos transversais na base, no meio e na parte superior (ponta) do tronco. Para as raízes, toda a biomassa obtida foi homogeneizada, sendo retiradas três amostras compostas de $300 \mathrm{~g}$.

Posterior à pesagem dos compartimentos em campo, os materiais foram acondicionados em sacos plásticos e encaminhados para o laboratório, onde foram secos em estufa de renovação e circulação de ar à temperatura de $75^{\circ} \mathrm{C}$ até atingir peso constante, para a determinação do peso seco (Watzlawick \& Caldeira, 2004). Os percentuais de biomassa das amostras de cada compartimento foram calculados com base na relação: teor de matéria seca $=$ (peso seco / peso verde) * 100 (Urbano et al., 2008).

\section{Estimativa da biomassa}

Três modelos aritméticos e três logarítmicos, frequentemente empregados nesses estudos, foram comparados com dois modelos desenvolvidos por procedimento Stepwise, um com a variável dependente sem transformação na unidade original e outra com a variável dependente logaritmizada (Tabela 1), para descrever a biomassa total das árvores e dos compartimentos (Segura \& Andrade, 2008; Miranda et al., 2011; Souza et al., 2014).

O método "Stepwise regression" permite que uma variável independente introduzida no modelo em um estágio possa ser eliminada num estágio posterior, caso ela não seja mais útil no conjunto com as variáveis adicionadas em estágios posteriores, ou seja, se ela deixar de ser significativa com a inclusão de outra variável no modelo. O processo termina quando não 
há mais variáveis para serem adicionadas ou retiradas do modelo (Bezerra et al., 2007). O nível de confiança de $95 \%$ foi utilizado para a construção das equações por Stepwise. Os modelos logarítmicos tiveram a discrepância logarítmica corrigida aplicando-se o fator de correção de Meyer e as estatísticas de ajuste recalculadas (Souza et al., 2013).

No ajuste dos modelos foram empregados dados de $80 \%$ das árvores amostradas (80), utilizando-se os $20 \%$ restantes (20) para validação do modelo selecionado. O total de árvores selecionadas para validação foi tomado observando-se a frequência de árvores por classe de diâmetro $\left(\mathrm{d}_{0,3}\right)$, sendo que, da primeira para a última classe (amplitude de $1 \mathrm{~cm}$ ), retirou-se sucessivamente a quantidade de árvores: 1, 4, 4, 6, 4 e 1 árvores, de forma sistemática semelhante ao empregado por Silveira (2009).

No presente estudo, para que cada modelo selecionado fosse considerado válido e para testar sua eficiência, utilizou-se o teste de aderência de qui-quadrado $\left(x^{2}\right)$ ao nível de $95 \%$ de confiança.

A variável dependente (biomassa seca) dos componentes foi expressa em $\mathrm{kg}$. As variáveis independentes testadas foram $\mathrm{d}_{0,3}, \mathrm{~h}$, hic e cc; bem como suas modificações e interações na forma simples, quadrática, cúbica, inversa e logarítmica.

\section{Critérios estatísticos para seleção de modelos}

As equações foram avaliadas com o coeficiente de determinação ajustado $\left(\mathrm{R}^{2}{ }_{\mathrm{aj}}\right)$, erro-padrão da estimativa percentual $\left(\mathrm{S}_{\mathrm{yx}} \%\right)$ e distribuição gráfica de resíduos percentuais. Os cálculos foram realizados no SAS v. 9.1 (SAS Institute, 2004).

Tabela 1. Modelos matemáticos testados para estimativa de biomassa total e dos compartimentos em regeneração natural em plantio de Pinus taeda.

\begin{tabular}{clc}
\hline $\mathrm{N}^{\mathrm{o}}$ & \multicolumn{1}{c}{ Modelo } & Autores \\
\hline 1 & $B S=\beta_{0}+\beta_{1} d_{0,3}$ & Berkhout \\
2 & $B S=\beta_{0}+\beta_{1} d_{0,3}^{2} h$ & Spurr \\
3 & $B S=\beta_{0}+\beta_{1} d_{0,3}^{2}+\beta_{2} d_{0,3} h+\beta_{3} d_{0,3}^{2} h$ & Meyer \\
4 & & Stepwise Aritmética \\
5 & $\ln B S=\beta_{0}+\beta_{1} \ln d_{0,3}$ & Husch \\
6 & $\ln B S=\beta_{0}+\beta_{1} \ln d_{0,3}^{2} h$ & Spurr modificado \\
7 & $\ln B S=\beta_{0}+\beta_{1} \ln d_{0,3}+\beta_{2} \ln h$ & Schumacher-Hall \\
8 & & Stepwise-Logarítmica \\
\hline
\end{tabular}

Em que: $B S=$ biomassa seca; $L n=$ logaritmo natural; $d_{0,3}=$ diâmetro a $0,3 \mathrm{~m}$ do nível do solo; $h=$ altura total; $\mathrm{d}_{03} \mathrm{~h}=$ combinação entre a variável diâmetro a $0,3 \mathrm{~m}$ do nível do solo e altura total; $\mathrm{d}^{2}{ }_{0,3} \mathrm{~h}=$ combinação entre a variável diâmetro a $0,3 \mathrm{~m}$ do nível do solo ao quadrado e altura total.

\section{Resultados e discussão}

A quantidade de biomassa fracionada nos compartimentos apresentou grande variação, o que está diretamente associado ao tamanho da árvore expresso pelas variáveis diâmetro a $0,3 \mathrm{~m}$ do nível do solo $\left(\mathrm{d}_{0,3}\right)$; altura total $(\mathrm{h})$; altura de inserção da copa, correspondente ao primeiro galho vivo (hic); e comprimento de copa (cc). O coeficiente de variação oscilou entre $16,46 \%$ para a biomassa contida no fuste e 49,74\% para a biomassa das acículas das árvores amostradas (Tabela 2).

A alocação de biomassa nos compartimentos decresceu a partir do compartimento do fuste $(61,52 \%)$; raízes $(15,09 \%)$, galhos $(14,13 \%)$ e acículas $(9,26 \%)$. Esses valores foram semelhantes aos encontrados por Schumacher et al. (2013) em povoamentos de Pinus taeda, que foi de $69,1 \%$ para o fuste; $17,1 \%$ para galhos vivos; $3,4 \%$ para acículas e $3,8 \%$ para galhos mortos (Tabela 2).

Tabela 2. Variáveis dendrométricas e biomassa seca dos compartimentos da parte aérea e das raízes em porcentagem dos indivíduos de regeneração natural amostrados em povoamento de Pinus taeda L. na Floresta Nacional de Três Barras, SC.

\begin{tabular}{cccccc}
\hline Variáveis & Mínimo & Média & Mediana & Máximo & $\mathrm{CV} \%$ \\
acículas & 1,56 & 9,26 & 8,87 & 20,07 & 49,74 \\
galhos & 4,46 & 14,13 & 13,03 & 36,95 & 38,61 \\
fuste & 33,68 & 61,52 & 62,74 & 85,05 & 16,46 \\
raízes & 7,47 & 15,09 & 14,68 & 40,65 & 35,04 \\
$\mathrm{~d}_{0,3}$ & 0,96 & 2,58 & 2,38 & 6,05 & 41,92 \\
$\mathrm{~h}$ & 1,46 & 3,46 & 3,13 & 7,40 & 39,86 \\
$\mathrm{cc}$ & 0,38 & 1,33 & 1,14 & 3,90 & 54,60 \\
hic & 0,20 & 2,13 & 1,93 & 6,00 & 46,11 \\
\hline
\end{tabular}

Em que: $\mathrm{d}_{0,3}=$ diâmetro a $0,3 \mathrm{~m}$ do nível do solo; $\mathrm{h}=$ altura total; $\mathrm{cc}=$ comprimento de copa; hic = altura de inserção da copa.

No presente estudo, as árvores selecionadas estabeleceram-se em ambiente com baixa incidência de luminosidade, favorecendo o desenvolvimento pouco expressivo dos compartimentos acima da base da copa, influenciando, deste modo, no aumento da produção relativa do tronco. Segundo Schumacher (1992) durante a fase inicial de desenvolvimento de uma floresta, boa parte dos carboidratos é canalizada para a produção de biomassa da copa, mas com o passar do tempo, quando as copas começam a competir entre si por espaço, a 
produção relativa do tronco aumenta e a de folhas e ramos diminui gradativamente.

Os modelos para predição da biomassa seca, ajustados segundo os compartimentos apresentaram $\mathrm{R}_{\text {aj }}$ variando de 0,863 a 0,921 (Tabela 3). Embora tenha se observado pequena amplitude de variação nestas estatísticas, a melhor performance para estimar a biomassa seca total foi obtida pela equação desenvolvida pelo procedimento Stepwise (8) com $\mathrm{R}_{\text {aj }}{ }^{2}=0,915$ e $\mathrm{S}_{\mathrm{yx}} \%=27,6$ e sem tendências ao longo da linha estimativa (Figura 1). Neste caso, a variável dependente foi logaritmizada e o fator de correção de Meyer calculado foi de 1,024. A equação foi considerada válida pelo teste de aderência de qui-quadrado $\left(x^{2}{ }_{\text {cal. }} 6,3<x^{2}{ }_{\text {tab. }} 31,4\right)$. O modelo de Meyer, cujo coeficiente de determinação ajustado e erro padrão da estimativa percentual apresentou os melhores valores, teve os parâmetros $\beta_{0}$ e $\beta_{3}$ não significativos, comprometendo a seleção do modelo para a estimativa da biomassa total. A equação aritmética desenvolvida pelo procedimento Stepwise (4), representada pela expressão $P S T=-0,2733+0,00770 \mathrm{~d}^{2}{ }_{0,3}+0,1288 h$ apresentou valores estatísticos semelhantes $\left(\mathrm{R}^{2}{ }_{\text {aj }}=\right.$ 0,$\left.921 ; \mathrm{S}_{\mathrm{yx}} \%=26,5\right)$ ao modelo selecionado (8), porém, a análise gráfica dos resíduos mostrou alta dispersão dos resíduos com tendência a subestimativa nas árvores com $\mathrm{d}_{0,3}$ menor que $5 \mathrm{~cm}$.

Para estimar a biomassa seca do fuste, ao considerar todos os critérios de seleção, a equação logarítmica (8) desenvolvida pelo procedimento Stepwise, apresentou os melhores resultados de ajuste e precisão $\left(\mathrm{R}^{2}{ }_{\mathrm{aj}}=\right.$ 0,$\left.905 ; \mathrm{S}_{\mathrm{yx}} \%=31,4\right)$, com a distribuição de resíduos sem tendências ao longo da linha estimativa (Figura 1). A equação foi validada pelo teste de aderência de qui-quadrado, com valores de $x^{2}$ calculado iguais a 3,57, inferior ao valor tabelado de 31,4. O fator de correção de Meyer foi de 1,031. Ressalta-se que, embora a equação 4 tenha apresentado melhores ajustes e precisão $\left(\mathrm{R}^{2}{ }_{\mathrm{aj}}=0,912 ; \mathrm{S}_{\mathrm{yx}} \%=30,2\right)$, a análise gráfica demonstrou dispersão dos resíduos com tendência de superestimativas mais expressivas quando comparado com a equação 8 (Figura 1).

Para estimar a biomassa seca das acículas e galhos, o modelo de Husch (5) apresentou os melhores ajustes e precisão, com $\mathrm{R}_{\text {aj. }}^{2}>0,70$ e $\mathrm{S}_{\mathrm{yx}} \%<57$ (Tabela 3). A análise gráfica demonstrou alta dispersão dos resíduos com tendência de superestimativas nas classes de $d_{0,3}$ entre 2 a $3 \mathrm{~cm}$ (Figura 1). Ambos os compartimentos, acículas e galhos, tiveram equações validadas pelo teste de qui-quadrado para $x^{2}$ tab $\geq 31,4$, com $x^{2}$ de 0,89 e 0,96, e fator de correção de Meyer de 1,226 e 1,096, respectivamente.

A dificuldade em estimar a biomassa seca das folhas e galhos, também foi relatada por Urbano et al. (2008). Para melhoria da capacidade preditiva destes modelos, alguns autores recomendam a inclusão de variáveis associadas ao tamanho da copa (Mello \& Gonçalves, 2008). Entretanto, neste estudo as variáveis associadas às dimensões de copa não proporcionaram melhor ajuste, não tendo sido selecionadas quando utilizado o procedimento Stepwise. Este resultado, possivelmente, possa ser atribuído a grande variabilidade destas dimensões no interior do povoamento florestal, ocasionada pela baixa incidência de luz e alta competição.

O modelo de Berkhout $\left(\mathrm{R}_{\text {aj. }}^{2}=0,667 ; \mathrm{S}_{\mathrm{yx}} \%=45,3\right)$ foi selecionado para a estimativa da biomassa seca das raízes, sendo utilizada apenas a variável $\mathrm{d}_{0,3}$. O modelo foi gerado com o emprego do procedimento Stepwise de regressão. Na Figura 1, verifica-se a inexistência de tendência ao longo da linha estimativa. $O$ teste de qui-quadrado também validou esta equação $\left(x^{2}=1,27\right)$.

As variáveis $d_{0,3}$ e $h$ nas equações da biomassa seca total e do fuste, bem como a variável $\mathrm{d}_{0,3}$ na estimativa dos demais compartimentos são variáveis explicativas de fácil obtenção. Apesar de a altura de algumas espécies serem de difícil medição e causar erros em sua obtenção (Campos \& Leite, 2002) esta pode ser estimada por meio de equação de regressão com base na relação hipsométrica (Finger, 1992). No entanto, essas medidas podem ser adquiridas diretamente em árvores de regeneração natural de pequeno porte, com maior acuracidade.

$\mathrm{Na}$ estimativa da biomassa seca das acículas, galhos e raízes, a variável altura não trouxe melhoria no ajuste. Estes resultados podem estar associados aos fatores sombreamento, competição, desenvolvimento da copa e às diferentes fases de expansão foliar (Salis et al., 2006).

As equações tradicionais encontradas na literatura, de forma geral, revelaram-se menos acuradas que as equações aritméticas e logarítmicas ajustadas pelo procedimento Stepwise, em conformidade com estudos de modelagem de biomassa seca realizados por Miranda et al. (2011) e Souza et al. (2014), reforçando a importância e a melhoria que o método Stepwise representa nos estudos de modelagem (Souza et al., 2013). 
Tabela 3. Equações ajustadas para biomassa total, dos compartimentos e estatísticas de ajuste e precisão de regeneração natural amostrada em povoamento de Pinus taeda L. na Floresta Nacional de Três Barras, SC.

\begin{tabular}{|c|c|c|c|c|}
\hline Eq. & Equação & $\mathbf{R}^{2}{ }_{\text {aj. }}$ & $S_{y x} \%$ & Fc \\
\hline 1 & $P S T=-0,8603+0,6336 d_{0,3}$ & 0,877 & 33,1 & - \\
\hline 2 & $P S T=0,2926+0,016 d_{0,3}^{2} h$ & 0,875 & 33,4 & - \\
\hline 3 & $P S T=-0,0879 *+0,0571 d_{0,3}^{2}+0,0506 d_{0,3} h-0,0029 * d_{0,3}^{2} h$ & 0,920 & 26,7 & - \\
\hline 4 & $P S T=-0,2733+0,0770 d_{0,3}^{2}+0,1288 h$ & 0,921 & 26,5 & - \\
\hline 5 & $\ln (P S T)=-2,5755+2,2174 \ln d_{0,3}$ & 0,873 & 33,6 & 1,035 \\
\hline 6 & $\ln (P S T)=-2,29279-0,7833 \ln d_{0,3}^{2} h$ & 0,863 & 34,9 & 1,027 \\
\hline 7 & $\ln (P S T)=-2,8876-1,6577 \ln d_{0,3}+0,6813 \ln h$ & 0,865 & 34,7 & 1,028 \\
\hline 8 & $\ln (P S T)=-3,1194-0,0198 d_{03} h+0,9189 \ln d^{2} h$ & 0,915 & 27,6 & 1,024 \\
\hline 1 & $P S A=-0,0711+0,0541 d_{0,3}$ & 0,709 & 54,6 & - \\
\hline 2 & $P S A=0,0264+0,0012 d_{0,3}^{2} h$ & 0,738 & 51,8 & - \\
\hline 3 & $P S A=0,0133 *+0,0071 d_{0,3}^{2}-0,0019 * d_{0,3} h+0,0006 * d_{0,3}^{2} h$ & 0,758 & 49,8 & - \\
\hline 4 & $P S A=0,0015^{*}+0,0087 d_{0,3}^{2}$ & 0,759 & 49,7 & - \\
\hline 5 & $\ln (P S A)=-5,0371+2,2417 \ln d_{0,3}$ & 0,726 & 53,0 & 1,226 \\
\hline 6 & $\ln (P S A)=-5,3127+0,7343 \ln d_{0,3}^{2} h$ & 0,703 & 55,1 & 1,245 \\
\hline 7 & $\ln (P S A)=-4,9325+2,3292 \ln d_{0,3}-0,2283 * \ln h$ & 0,719 & 53,7 & 1,228 \\
\hline 8 & $\ln (P S A)=-4,9069+0,7225 \ln d^{2}{ }_{0.3} h i c$ & 0,704 & 55,1 & 1,214 \\
\hline 1 & $P S G=-0,1159+0,0858 d_{0,3}$ & 0,760 & 49,3 & - \\
\hline 2 & $P S G=0,0432+0,00185 d_{0,3}^{2} h$ & 0,689 & 56,2 & - \\
\hline 3 & $P S G=-0,0133 *+0,0201 d_{0,3}^{2}-0,0009 * d_{0,3} h-0,0008 * d^{2}{ }_{0,3} h$ & 0,787 & 46,4 & - \\
\hline 4 & $P S G=0,0015 *+0,0133 d_{0,3}^{2}$ & 0,781 & 47,1 & - \\
\hline 5 & $\ln (P S G)=-4,5186+2,1221 \ln d_{0,3}$ & 0,767 & 48,6 & 1,096 \\
\hline 6 & $\ln (P S G)=-5,3127+0,7343 \ln d_{0,3}^{2} h$ & 0,709 & 54,3 & 1,107 \\
\hline 7 & $\ln (P S G)=-4,4965+2,1616 \ln d_{0,3}-0,0481 * \ln h$ & 0,766 & 48,6 & 1,097 \\
\hline 8 & $\ln (P S G)=-4,5186+2,1221 \ln d_{0,3}$ & 0,767 & 48,6 & 1,096 \\
\hline 1 & $P S F=-0,6184+0,4329 d_{0,3}$ & 0,843 & 40,5 & - \\
\hline 2 & $P S F=0,1621+0,0095 d_{0,3}^{2} h$ & 0,878 & 35,6 & - \\
\hline 3 & $P S F=-0,0811 *+0,0177 * d_{0,3}^{2}+0,0459 d_{0,3} h-0,0008 * d_{0,3}^{2} h$ & 0,913 & 30,0 & - \\
\hline 4 & $P S F=-0,0655+0,0551 d_{0,3} h$ & 0,912 & 30,2 & - \\
\hline 5 & $\ln (P S F)=-3,1851+2,3433 \ln d_{0,3}$ & 0,848 & 39,8 & 1,055 \\
\hline 6 & $\ln (P S F)=-3,5861+0,8376 \ln d_{0,3}^{2} h$ & 0,852 & 39,3 & 1,035 \\
\hline 7 & $\ln (P S F)=-3,6943+1,4301 \ln d_{0,3}+1,1116 \ln h$ & 0,843 & 40,5 & 1,034 \\
\hline 8 & $\ln (P S F)=-3,5973-0,2755 d_{0,3}+1,0861 \ln d^{2}{ }_{0,3} h$ & 0,905 & 31,4 & 1,031 \\
\hline 1 & $P S R=-0,0548+0,0608 d_{0,3}$ & 0,667 & 45,3 & - \\
\hline 2 & $P S R=0,0609+0,0012 d_{0,3}^{2} h$ & 0,525 & 54,1 & - \\
\hline 3 & $P S R=-0,0067 *+0,0122 d_{0,3}^{2}+0,0075 d_{0,3} h-0,0018^{*} d_{0,3}^{2} h$ & 0,649 & 46,5 & - \\
\hline 4 & $P S R=-0,0548+0,0608 d_{0,3}$ & 0,667 & 45,3 & - \\
\hline 5 & $\ln (P S R)=-4,2181+1,8682 \ln d_{0,3}$ & 0,521 & 54,4 & 1,082 \\
\hline 6 & $\ln (P S R)=-4,4801+0,6479 \ln d_{0,3}^{2} h$ & 0,486 & 56,3 & 1,087 \\
\hline 7 & $\ln (P S R)=-4,2624+1,7889 \ln d_{0,3}+0,0965 \ln h$ & 0,509 & 55,0 & 1,083 \\
\hline 8 & $\ln (P S R)=-0,7283-4,11321 / d_{0,3}$ & 0,666 & 45,4 & 1,073 \\
\hline
\end{tabular}

Em que: * = valores dos coeficientes não-significativos ao nível de $95 \%$ de significância; $\mathrm{R}_{\mathrm{aj}}^{2}=$ coeficiente de determinação ajustado; $\mathrm{S}_{\mathrm{yx}}=$ erro padrão da estimativa; $\mathrm{Fc}=$ fator de correção de Meyer; $\mathrm{PST}=$ peso seco total; $\mathrm{PSA}=$ peso seco das acículas; $\mathrm{PSG}=$ peso seco dos galhos; $\mathrm{PSF}=$ peso seco do fuste; $\mathrm{PSR}=$ peso seco das raízes; $\mathrm{Ln}=$ logaritmo natural; $\mathrm{d}_{03}=$ diâmetro a $0,3 \mathrm{~m}$ do nível do solo; $\mathrm{h}=$ altura total; $\mathrm{hic}=$ altura de inserção da copa; $\mathrm{d}_{0,3} \mathrm{~h}=$ variável combinada; $\mathrm{d}_{0,3}^{2} \mathrm{hic}=$ variável transformada e combinada; $\mathrm{d}_{0,3}^{2} \mathrm{~h}$ = variável transformada e combinada. 

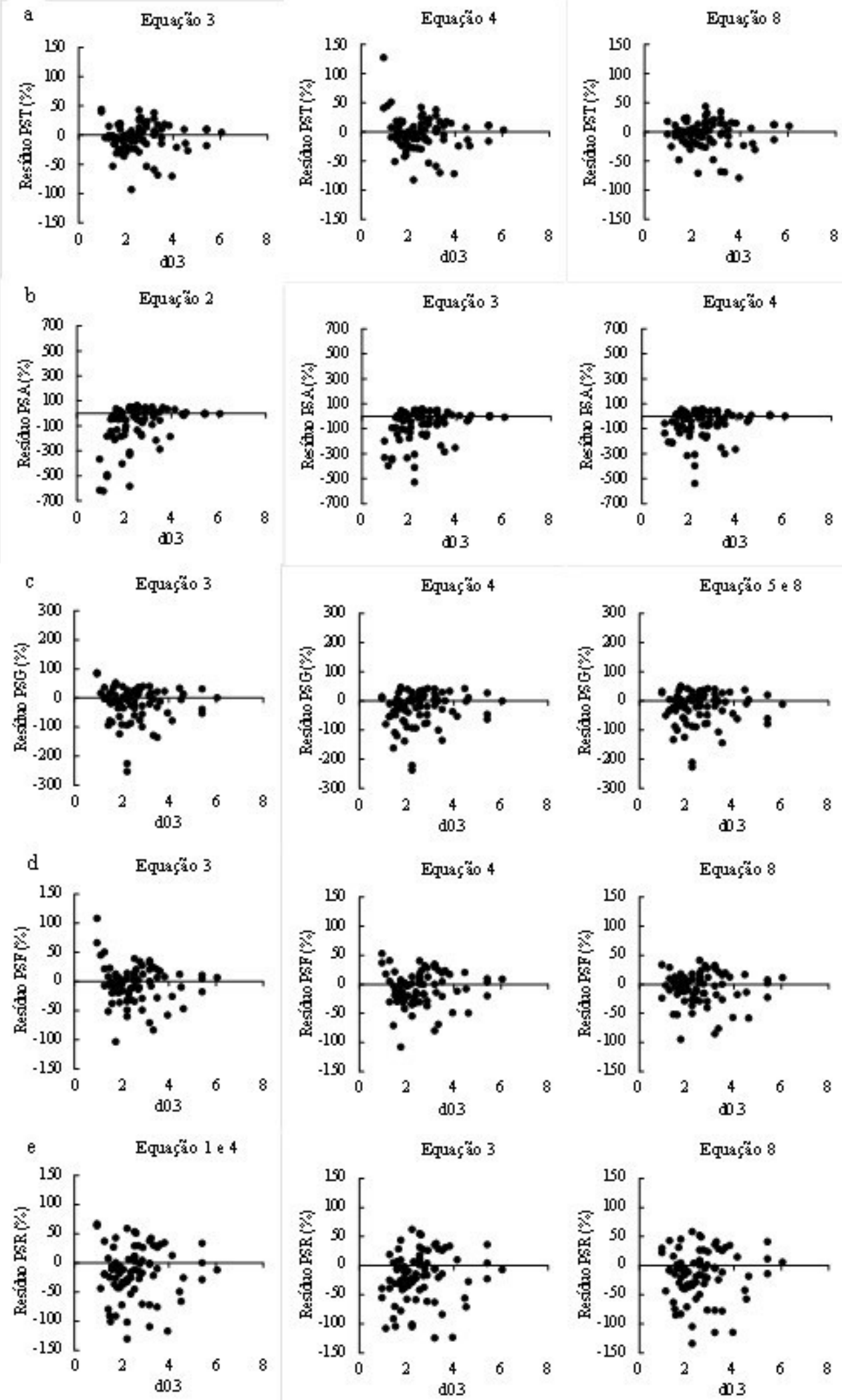

Figura 1. Resíduo percentual das três equações de melhor ajuste e precisão desenvolvidas para a estimativa da biomassa seca total (a), acículas (b), galhos (c), fuste (d) e raízes (e) da regeneração natural em povoamento de Pinus taeda L. na Floresta Nacional de Três Barras, SC.) 


\section{Conclusão}

As equações selecionadas diferem de acordo com o compartimento da árvore.

As equações logarítmicas desenvolvidas pelo procedimento Stepwise apresentam as melhores estimativas para a biomassa aérea total e do fuste e o modelo de Husch para a estimativa do peso seco das acículas e galhos.

O modelo 4 desenvolvido pelo procedimento Stepwise, semelhante ao modelo de Berkhout, diferindo apenas por apresentar o $\mathrm{d}_{0,3}$ como variável independente, mostrou-se o mais adequado para a predição da biomassa do sistema radicular.

As variáveis que descrevem as dimensões de copa não contribuem com o poder de descrição das equações para qualquer dos compartimentos estudados.

Todos os modelos apresentam valores elevados de $\mathrm{R}_{\text {aj. }}^{2}$ e altos valores residuais decorrente da alta variabilidade natural dos dados amostrados, porem, nenhuma equação apresentou estimativa tendenciosa.

\section{Referências}

Batista, J. L. F. et al. Quantificação de recursos florestais: árvores, arvoredos e florestas. São Paulo: Oficina de Textos, 2014. 384 p.

Bezerra, A. M. et al. Seleção de variáveis em modelos matemáticos dos parâmetros de cultivo do camarão marinho Litopenaeus vannamei. Pesquisa Agropecuária Brasileira, v. 42, n. 3, p. 385391, 2007. DOI: 10.1590/S0100-204X2007000300012.

Campos, J. C. C. \& Leite, H. G. Mensuração florestal: perguntas e respostas. Viçosa, MG: Ed. da UFV, 2002. 407 p.

Campos, M. A. A. Balanço de biomassa e nutrientes em povoamentos de Ilex paraguariensis: avaliação na safra e na safrinha. 1991. 160 f. Dissertação (Mestrado em Ciências Florestais) - Universidade Federal do Paraná, Curitiba.

Carbonera Pereira, J. et al. Produção de biomassa em um povoamento de Acacia mearnsii De Wild no Estado do Rio Grande do Sul. Revista Árvore, v. 21, n. 4, p. 521-526, 1997.

Epagri (Florianópolis, SC). Dados e informações biofísicas da Unidade de planejamento Regional Planalto Norte Catarinense - UPR 4. Florianópolis, 2001.

Fayolle, A. et al. Tree allometry in Central Africa: testing the validity of pantropical multi-species allometric equations for estimating biomass and carbon stocks. Forest Ecology and Management, v. 305, p. 29-37, 2013. DOI: 10.1016/j.foreco.2013.05.036.

Finger, C. A. G. Fundamentos de biometria florestal. Santa Maria, RS: UFSM/FATEC/CEPEF, 1992. 269 p.

Lima, A. L. de et al. Estoques de carbono e emissões de gases de efeito estufa na agropecuária brasileira. Brasília, DF: Embrapa, 2012. 347 p.
Marques, A. C. Planejamento da paisagem da Floresta Nacional de Três Barras (Três Barras - SC): subsídios ao plano de manejo. 2007. 145 f. Dissertação (Mestrado em Geografia) - Universidade Federal do Paraná, Curitiba.

Mello, S. L. \& Gonçalves, J. L. M. Equações para estimar a biomassa da parte aérea e do sistema radicular em povoamentos de Eucalyptus grandis em sítios com produtividades distintas. Revista Árvore, v. 32, n. 1, p. 101-111, 2008. DOI: 10.1590/S010067622008000100012 .

Miranda, D. L. C. de et al. Equações alométricas para estimativa de biomassa e carbono em árvores de reflorestamentos de restauração. Revista Árvore, v. 35, n. 3, supl. 1, p. 679-689, 2011. DOI: 10.1590/ S0100-67622011000400012.

Ritchie, M. W. et al. Aboveground tree biomass for Pinus ponderosa in Northeastern California. Forests, v. 4, n. 1, p. 179-196, 2013. DOI: $10.3390 / \mathrm{f} 4010179$.

Salis, S. M. et al. Estimating the aboveground biomass and wood volume of savana wooklands in Brazil's Pantanal wetlands based on allometric correlations. Forest Ecology and Management, v. 228, n. 103, p. 61-68, 2006. DOI: 10.1016/j.foreco.2006.02.025.

SAS Institute. The SAS System for Windows. Cary, 2004.

Schikowski, A. B. et al. Modelagem do crescimento e de biomassa individual de Pinus. Pesquisa Florestal Brasileira, v. 33, n. 75, p. 269-278, 2013. DOI: 10.4336/2013.pfb.33.75.503.

Schumacher, M. V. et al. Biomassa e nutrientes no corte raso de um povoamento de Pinus taeda L. de 27 anos de idade em Cambará do Sul - RS. Ciência Florestal, v. 23, n. 2, p. 321-332, 2013. DOI: $10.5902 / 198050989278$.

Schumacher, M. V. Aspectos da ciclagem de nutrientes e do microclima em talhões de Eucalyptus camaldulensis Dehnh Eucalyptus grandis Hill ex Maiden e Eucalyptus torelliana F. Muell. 1992. 87 f. Dissertação (Mestrado em Ciências Florestais) Escola Superior de Agricultura Luiz de Queiroz, Piracicaba.

Segura, M. \& Andrade, H. J. ¿Cómo construir modelos alométricos de volumen, biomasa o carbono de espécies leñosas perennes? Agroforestería de las Américas, n. 46, p. 89-96, 2008.

Silveira, P. Ajuste de modelos matemáticos para estimar biomassa aérea em Floresta Ombrófila Densa. Floresta, v. 30, n. 4, p. 743-752, 2009. DOI: $10.5380 /$ rf.v39i4.16309.

Silveira, P. et al. O estado da arte na estimativa de biomassa e carbono em formações florestais. Floresta, v. 38, n. 1, 2008. DOI: 10.5380/ rf.v38i1.11038.

Soares, C. P. B. et al. Dendrometria e inventário florestal. 2. ed. Viçosa, MG: Ed. da UFV, 2012. 272 p.

Souza, R. F. et al. Modelagem da biomassa total e da lenha por unidade de área para bracatingais nativos. Revista Árvore, v. 38, n. 1, p. 53-62, 2014. DOI: 10.1590/S0100-67622014000100005.

Souza, R. F. de. et al. Modelagem do carbono orgânico total e da lenha por unidade de área para bracatingais nativos. Ciência Florestal, v. 23, n. 1, p. 117-127, 2013. DOI: 10.5902/198050988446.

Urbano, E. et al. Modelagem da biomassa aérea em bracatingais nativos da região metropolitana de Curitiba. Floresta, v. 38, n. 2, p. 361-372, 2008. DOI: 10.5380/rf.v38i2.11631. 
Watzlawick, L. F. \& Caldeira, M. V. W. Estimativa de biomassa e carbono orgânico em povoamentos de Pinus taeda L. com diferentes idades. Biomassa \& Energia, v. 1, n. 4, p. 371-380, 2004. 